\title{
Bibliometric Analysis of Cucumber (Cucumis sativus L.) Research Publications from Horticulture Category Based on the Web of Science
}

Bao-Zhong Yuan

College of Plant Science and Technology, Huazhong Agricultural University, Wuhan City, Hubei Province, PR China, 430070

Zhi-Long Bie

College of Horticulture and Forestry, Huazhong Agricultural University, Wuhan City, Hubei Province, PR China, 430070

\section{Jie Sun}

Library of Huazhong Agricultural University, Wuhan City, Hubei Province, PR China, 430070

Additional index words. bibliometric analysis, cucumber, Cucumis sativus, horticulture category, VOSviewer, Web of Science

Abstract. Cucumber (Cucumis sativus L.) is an economically important vegetable crop that is cultivated worldwide. The current study aimed to identify and analyze the 2030 articles and review article about cucumber research from the horticulture category of the VOS viewer Web of Science. Bibliometric data were analyzed by bibliometric science mapping and visualization tools. Articles mainly written in English (1884; $92.81 \%$ ) were from 5630 authors, 80 countries or territories, and 1094 organizations; they were published in $\mathbf{4 6}$ journals and book series. The top five core journals are $\mathrm{Sci}$ entia Horticulturae (337; 16.60\%), HortScience (265; 13.05\%), Journal of the American Society for Horticultural Science (239; 11.77\%), European Journal of Plant Pathology (195; 9.61\%), and Horticulture Journal (Journal of the Japanese Society for Horticultural Science) (157; 7.73\%). These journals each published more than 157 articles. The top five countries and regions were the United States, People's Republic of China, Japan, South Korea, and India. The top five organizations were the University of Wisconsin, North Carolina State University, U.S. Department of Agriculture-Agricultural Research Service, Michigan State University, and Nanjing Agricultural University. The top five authors are Todd C. Wehner (Wehner, TC), Jack E. Staub (Staub, JE), Yiqun Weng, R.L. Lower, and S. Tachibana; each published more than 24 articles. All keywords used for cucumber research in the horticulture category were separated into eight clusters for different research topics. Visualizations offer exploratory information regarding the current state in a scientific field or discipline as well as indicate possible developments in the future. This review could be a valuable guide for designing future studies.

The cucumber (Cucumis sativus L.), which belongs to the Cucurbitaceae family, is a commonly consumed vegetable. It is an economically important crop that is widely cultivated throughout the world. Cucumber plants often experience biotic and abiotic stresses during its developmental life cycle, thus leading to reductions in yield and quality (Wang et al., 2015). Cucumber plants suffer from several

Received for publication 23 June 2021. Accepted for publication 2 Aug. 2021.

Published online 21 October 2021.

This work was supported by Hubei Provincial Natural Science Foundation of China (2019CFA017). B.-Z.Y. and Z.-L.B. are the corresponding authors. E-mail: yuanbz@mail.hzau.edu.cn or biezl@mail. hzau.edu.cn.

This is an open access article distributed under the CC BY-NC-ND license (https://creativecommons. org/licenses/by-nc-nd/4.0/). diseases, such as downy mildew, powdery mildew (PM), anthracnose, and cucumber mosaic virus, which limit crop production. Developing resistance to these diseases is a major subject of cucumber plant breeding. Cucumber is a potential model plant candidate for the Cucurbitaceae family and would provide new scientific knowledge through molecular analysis (Nanasato and Tabei, 2020). PM is a destructive foliar disease with wide distribution and rapid spread that causes substantial yield losses. The long-term planting and variable adaptability of pathogens have led to the gradual decline in plant resistance. Consequently, the cultivation of durable and resistant cultivars is clearly the most economical and environmentally friendly method of controlling PM diseases during cucumber breeding (Chen et al., 2021). High yield can be achieved by improving cultural practices and by developing genetically superior cultivars. Highyielding cultivars, precision farming systems, increased use of chemicals for fertilization and weed and disease control, and proper training of the local farmers allowed for significant changes in agriculture (Gusmini and Wehner, 2008).

Cucumber is a popular vegetable worldwide. The total cucumber production (including gherkins) in 2018 was 75.2 million tons from 1.984 million cultivated hectares (FAOSTAT, 2020). China is one of the main countries producing cucumbers. The total cucumber production (including gherkins) in China in 2018 was 56.24 million tons from 1.044 million hectares, which accounted for $52.7 \%$ and $74.8 \%$ of the corresponding world totals, respectively. Cucumber (Cucumis sativus, L.) is widely grown in greenhouses in China as an offseason vegetable because of its high yield and economic benefits (Liu et al., 2021).

Cucumber (Cucumis sativus L.) is a major vegetable crop with important economic and biological value, and it serves as a model plant for studying several important biological processes (Che and Zhang, 2019). Cucumber was the first among major horticulture crops with a publicly available draft genome. Its relatively small, diploid genome, short life cycle, and self-compatible mating system offer advantages for genetic studies (Wang et al., 2020). The hypocotyl is an important agronomic trait of cucumber, and transplanting seedlings with a short hypocotyl is an effective method of increasing cucumber yield (Zhang et al., 2021). Cucumber is a potential model plant candidate for the Cucurbitaceae family and would provide new scientific knowledge through molecular analysis (Nanasato and Tabei, 2020).

The category of horticulture includes resources concerning the cultivation of flowers, fruits, vegetables, or ornamental plants in gardens, orchards, or nurseries (InCites Journal Citation Reports; Clarivate, 2021). Searching the publications by the topic keywords of "Cucumber" OR "Cucumis sativus L." and all the years published for article or review article types in the Web of Science, the top three Web of Science categories are Plant Sciences, Horticulture, and Agronomy. In this paper, publications that focused on the horticulture category were collected.

Bibliometric indicators have been frequently used to analyze scientific and technological production in different fields of knowledge. Bibliometric techniques have been adopted in some research, such as essential oil-bearing plants exposed to water stress (Kulak et al., 2019), grafting in horticultural plants (Belmonte-Ureña et al., 2020), scientific research about fungus Phakopsora pachyrhizi Sydow and Sydow affecting soybean [Glycine max (L.) Merrill] (Meira et al., 2020), highly cited articles in the Science Citation Index Expanded (subject category: horticulture) (Kolle et al., 2017), the research, innovation, and development of Corylus avellana (Raparelli and Lolletti, 2020), the berries on the top (Yeung et al., 2019), bibliometric analysis of French National Institute for Agricultural Research (INRA) publications 
Table 1. Document type and language of the publication about cucumber research from the horticulture category of the Web of Science.

\begin{tabular}{llcclrr}
\hline Rank & Document type & Records & \% of 2030 & Language & Records & \% of 2030 \\
\hline 1 & Article & 1999 & 98.47 & English & 1884 & 92.81 \\
2 & Review & 31 & 1.53 & Japanese & 58 & 2.86 \\
3 & Proceedings paper & 18 & 0.89 & Korean & 24 & 1.18 \\
4 & Early access & 4 & 0.20 & German & 23 & 1.13 \\
5 & Book chapter & 1 & 0.05 & Russian & 17 & 0.84 \\
6 & & & Portuguese & 14 & 0.69 \\
7 & & & Spanish & 6 & 0.30 \\
8 & & & Chinese & 2 & 0.10 \\
9 & & & Swedish & 2 & 0.10 \\
\hline
\end{tabular}

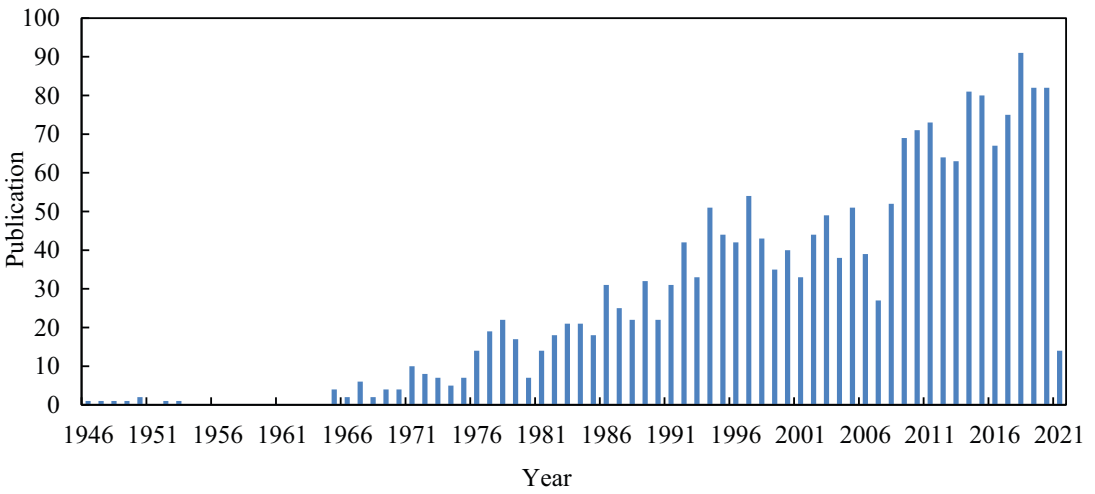

Fig. 1. Number of published articles about cucumber research from the horticulture category based on the Web of Science from 1946 to 2021.

about fruits and vegetables produced between 2002 and 2006 (Tatry et al., 2011), tree fruit growing in Germany (Dalla Via and Baric, 2012), trends in mango research (Kolle et al., 2018), and wine research and its relationship with wine production (Jamali et al., 2020). Others have researched soil and water conservation in the Loess Tableland-Gully region of China (Wang et al., 2019), advances in water use efficiency in agriculture, and sustainable water use in agriculture (Velasco-Muñoz et al., 2018a, 2018b). Rice with fertilizer has been analyzed based on Citespace (Sun and Yuan, 2019), the top articles about world rice research (Sun and Yuan, 2020a), library and information science (Sun and Yuan, 2020b), water resources (Sun and Yuan, 2020c), the agronomy category (Sun and Yuan, 2021), green and sustainable science and technology (Yuan and Sun, 2019), scientific research of maize or corn (Yuan and Sun, 2020a, 2020b), and global research of muskmelon (Cucumis melo L.) (Yuan et al., 2021).

Research is the way to the truth; therefore, innovations are important to finding something new or a new understanding to approach the truth. It is not helpful for researchers to duplicate the same problem without improving their research. It is the responsibility of the authors, reviewers, and editors to stop publishing such problems in journals. The aim of this study was to assess publications of research and review articles about cucumber (Cucumis sativus L.) from the horticulture category during all years using bibliometric science mapping and visualization tools. We assess the scattering of publications in citation databases, classification of topics, and progress over the years. Country input and author collaboration (coauthorship) are addressed. Special attention is dedicated to research topics and research fronts.

\section{Data and Methodology}

Web of Science. The Clarivate Analytics Web of Science (WoS) is the world's leading scientific citation search and analytical information platform and one of the world's largest and most comprehensive academic information resources covering more than 12,000 core academic journals. The numbers of publications in the WoS Core Collection were derived from the following databases: The Science Citation Index-Expanded (SCIE), 1900 to present; Social Science Citation Index (SSCI), 1900 to present; Conference Proceeding Citation Index-Science (CPCI-S), 2015 to present; Conference Proceedings Citation Index-Social Science \& Humanities (CPCI-SSH), 2015 to present; Current Chemical Reactions (CCR-EXPANDED), 1985 to present; and Index Chemicus (IC), 1993 to present.

Data collection and analysis. This study surveyed articles from the WoS Core Collection (1900-present) (data retrieval last performed on 29 Mar. 2021). We used the following keyword query: L.”)

Topic: ("Cucumber" or "Cucumis sativus

Then, the results were refined by the document type (article or review) and Web of Science category (horticulture).

There were 2030 articles from WoS Core Collection. Full records and cited references of the included articles were extracted using other reference software file formats and imported into VOSviewer (version 1.6.16; 2020; Leiden University, Leiden, the Netherlands) for further citation analysis. The impact factors (IFs; IF 2020 and IF 5-year) were taken from the Journal Citation Report (JCR) 2020, which was published in 2021 and had the latest data available.

VOSviewer. Visualizations (network and overlay) using VOSviewer were conducted for WoS data to determine the co-occurrence and clusters of connected publications, country input, and author collaboration (coauthorship), as well as clusters of inter-related research topics. We used VOSviewer to show the international collaboration between the authors, organizations, and countries, and the research trends through all keywords (Van Eck and Waltman, 2010). Default parameter values of the VOSviewer were usually used in the analysis. Items were represented by a label and a circle. The sizes of the circles reflect the weight of

Table 2. All Web of Science (WoS) categories and research areas for cucumber research from the horticulture category.

\begin{tabular}{|c|c|c|c|c|c|c|}
\hline Rank & WoS categories & TP & Ratio (\%) & Research Areas & TP & Ratio (\%) \\
\hline 1 & Horticulture & 2030 & 100 & Agriculture & 2030 & 100 \\
\hline 2 & Agronomy & 566 & 27.88 & Plant Sciences & 544 & 26.80 \\
\hline 3 & Plant Sciences & 544 & 26.80 & Genetics Heredity & 164 & 8.08 \\
\hline 5 & Food Science Technology & 69 & 3.40 & Biotechnology Applied Microbiology & 1 & 0.05 \\
\hline 6 & Biotechnology Applied Microbiology & 1 & 0.05 & Forestry & 1 & 0.05 \\
\hline 7 & Forestry & 1 & 0.05 & Nutrition Dietetics & 1 & 0.05 \\
\hline 8 & Nutrition Dietetics & 1 & 0.05 & Virology & 1 & 0.05 \\
\hline
\end{tabular}

Ratio refers to the percentage out of 2030.

$\mathrm{TP}=$ total publications. 
Table 3. Top 20 journals about cucumber research from the horticulture category of the Web of Science.

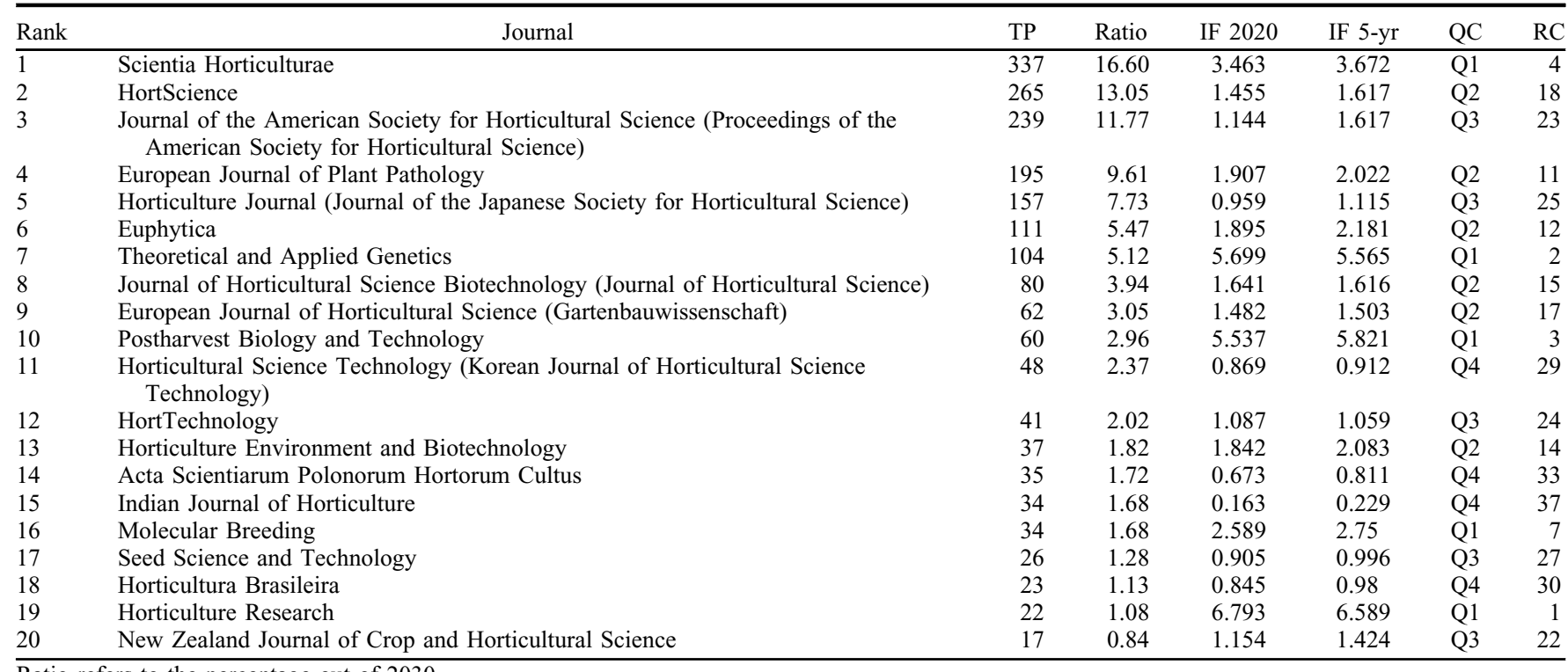

Ratio refers to the percentage out of 2030.

$\mathrm{IF}=$ impact factor; $\mathrm{QC}=$ quartile in the category; $\mathrm{RC}=$ rank in the horticulture category; $\mathrm{TP}=$ total publications.

Data are from the 2020 edition of Journal Citation Reports.

an item. Some items were not displayed to avoid overlapping. The colors in the network visualization represented clusters of similar items as calculated by the program. The distance between the items indicated the strength of the relationships.

\section{Results and Discussion}

Document types and language of publication. Based on Clarivate Analytics WoS Index, the 2030 articles were from SCIE (2030), and some papers also belong to CPCI-S (18), SSCI (6), and Book Citation Index-Science (1). The document types and languages are displayed in the Table 1 . Among the document types, there were 1999 articles $(98.47 \%)$ and 31 reviews $(1.53 \%)$, including 18 proceedings articles $(0.89 \%), 4$ early access articles $(0.20 \%)$, and 1 book chapter $(0.05 \%)$. The first article titled "The development of downy mildew-resistant cucumbers" (Barnes et al., 1946) was published in Proceedings of the American Society for Horticultural Science (47:357-360).

Almost all of the articles were published in English (1884; 92.81\%); others were published in Japanese $(58 ; 2.86 \%)$, Korean $(24$; $1.18 \%)$, German $(23 ; 1.13 \%)$, Russian (17; $0.84 \%)$, Portuguese $(14 ; 0.69 \%)$, Spanish (6; $0.30 \%$ ), Chinese $(2 ; 0.10 \%)$, and Swedish (2; $0.10 \%)$. English was the dominating language in the WoS. Scholars tend to publish their articles in English because they want them to be widely accepted. Most of the published documents were in the form of original research articles, and English was the most common language used (Khan et al., 2020).

Publication output. To determine the trend in cucumber research in the horticulture category of the WoS, a total of 2030 articles and reviews were obtained from the online version of the WoS database from 1946 to
2021 (Fig. 1). The most articles (91) were published in 2018. In the 1980s, 1990s, 2000 s, and $2010 \mathrm{~s}$, the article publication rates were $93.15 \%, 82.86 \%, 63.30 \%$, and $41.53 \%$, respectively. The $h$-index was initially proposed as a measure of a researcher's scientific output based on counting the number of publications $(\mathrm{N})$ by that researcher cited $\mathrm{N}$ or more times (Hirsch, 2005). For the 2030 articles, the $h$-index was 66 , and the average citation per item was 15.69 .

Web of Science categories and research areas. For cucumber research from the horticulture category of the WoS, there are nine WoS subject categories in the science edition (total of 254 categories) and eight research areas. Table 2 shows the WoS categories and research areas regarding the subject of cucumber research from the horticulture category of the WoS. The top five WoS categories include Horticulture $(2030 ; 100 \%)$, Agronomy $(566 ; 27.88 \%)$, Plant Sciences (544; 26.80\%), Genetics Heredity (164; $8.08 \%$ ) and Food Science Technology (69; $3.40 \%$ ). The top five research areas include Agriculture $(2030 ; 100 \%)$, Plant Sciences (544; 26.80\%), Genetics Heredity (164; $8.08 \%)$, Food Science Technology (69; $3.40 \%$ ), and Biotechnology Applied Microbiology $(1 ; 0.05 \%)$. The journals or articles may be classified as two or more categories in the WoS, which shows the multidisciplinary character of this research field (Elango and Ho, 2017, 2018). In the WoS, publications are also mapped to WoS categories, which are more detailed than areas (Stopar et al., 2021).

Core journals. Based on JCR 2020 data (published in 2021), there are 45 journals and one book series regarding cucumber research from the horticulture category of the WoS. The one book series is Advances in Virus Research. The top 20 core journals are displayed in Table 3. Based on the JCR 2020, there are 37 journals in the horticulture category.

The top 5, top 10, top 15 , and top 20 journals published $59.66 \%, 80.20 \%, 89.80 \%$, and $95.81 \%$ of the total articles, respectively. Scientia Horticulturae was the most productive journal, with 337 articles (16.60\%), followed by HortScience $(265 ; 13.05 \%)$, Journal of the American Society for Horticultural Science (Proceedings of the American Society for Horticultural Science; 257; 12.66\%), European Journal of Plant Pathology (195; 9.61\%), and Horticulture Journal (Journal of the Japanese Society for Horticultural Science; $157 ; 7.73 \%$ ). These journals each published more than 157 articles. Some journal names were changed; therefore, we combined these titles as the same journal; however, the total number of journals was calculated separately. Of the top 20 journals, there were 5 journals in quartile 1,6 journals in quartile 2,5 journals in quartile 3 , and 4 journals in quartile 4 (Table 3). White-Gibson et al. (2019) demonstrated the importance of publishing in the English language and in a journal with a high IF. A citation analysis is not a measurement of scientific quality, but it is reflective of importance (White-Gibson et al., 2019).

According to the publication data regarding the citation of 45 journals, 33 journals met the thresholds of 5 publications and 32 journals were connected to each other. The network of citations in the field of cucumber research from the horticulture category of the WoS is shown as six clusters with different colors in Fig. 2. The sizes of the circles reflect the total number of journal publication records. If journals were in the same cluster, then it was suggested that they published articles with 


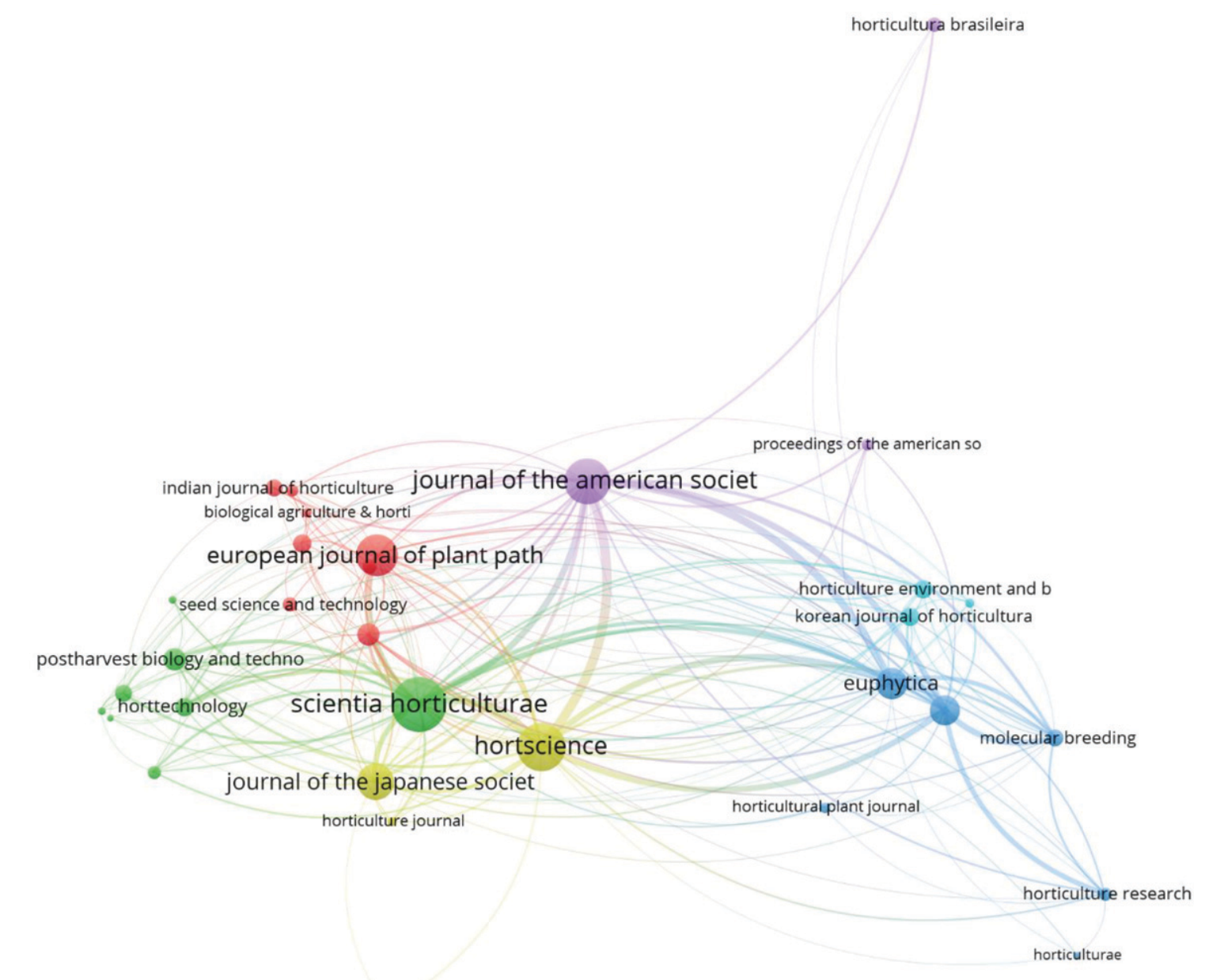

revista fitotecnia mexicana

\section{vosviewer}

Fig. 2. Network visualization maps of cited journals about cucumber research from the horticulture category of the Web of Science with 32 nodes and six clusters.

similar content and had close relations with each other.

Author coauthorship analysis. In general, internationally collaborative articles had the highest visibility and scientific impact, followed by interinstitutional collaborative articles, single-country articles, and single-author articles (Wambu and Ho, 2016). According to the publication data, a total of 5630 authors published 2030 publications. There were 141 authors who met the thresholds of five publications. However, only 57 authors were connected to each other. The network of authorship in the field of network visualization maps of authors of cucumber research from the horticulture category of the WoS is shown in Fig. 3. The sizes of the circles reflect the total number of records. If authors were in the same cluster, then it was suggested that they studied a similar field and had close cooperation with each other.

Details regarding the author information published in articles about cucumber from 1946 to 2021, along with citations, average citations, organization, and countries are provided in Table 4 . Table 4 shows the top 19 authors who published more than 12 articles, the total citations, average citations, organizations, and countries. Although we combined the same authors with different spellings, the total number of authors was calculated separately. The top five authors were Todd C. Wehner (Wehner, TC), Jack E. Staub (Staub, JE), Yiqun Weng, R.L. Lower, and S. Tachibana; each published more than 24 articles. The top five authors with a high number of citations per article were Yiqun Weng, Michael J. Havey (Havey, MJ), Jack E. Staub (Staub, JE), Yuhong Li, and Toshiki Asao (Asao, T). Their average citations per article totaled more than 20.75. Among the top 19 authors, there were nine from the United States, six from Japan, three from China, and one from India.

Country/region coauthorship analysis. There were 80 countries or regions contributing to the 2030 articles in this study. Table 5 lists the top 20 countries or regions where more than 17 publications originated. The top five countries that published articles were the United States, People's Republic of China, Japan, South Korea, and India. Italy, Israel, Netherlands, France, and Canada provided the highest number of citations per article.
We developed the international country coauthorship network map using VOSviewer software. We set the threshold as 5. There were 39 countries/regions meeting the requirements and 38 countries/regions connected to each other (Fig. 4). The VOSviewer software divided these 38 countries into seven clusters with different colors. The sizes of circles reflect the total number of records, and the distance between the countries indicates the strength of relationships. The different color groups and different clusters were formed based on countries.

The United States, People's Republic of China, Japan, South Korea, and India had the five biggest circles (Fig. 4). The first cluster consisted of 10 countries and regions (red color): India, Brazil, France, England, Belgium, Thailand, Taiwan, Hungary, Czech Republic, and Bangladesh. The second cluster consisted of seven countries or regions (green): Japan, South Korea, Iran, Norway, Finland, Sweden, and Denmark. The third cluster consisted of seven countries (blue): Poland, Israel, the Netherlands, Italy, Serbia, Lebanon, and Slovenia. The fourth cluster 


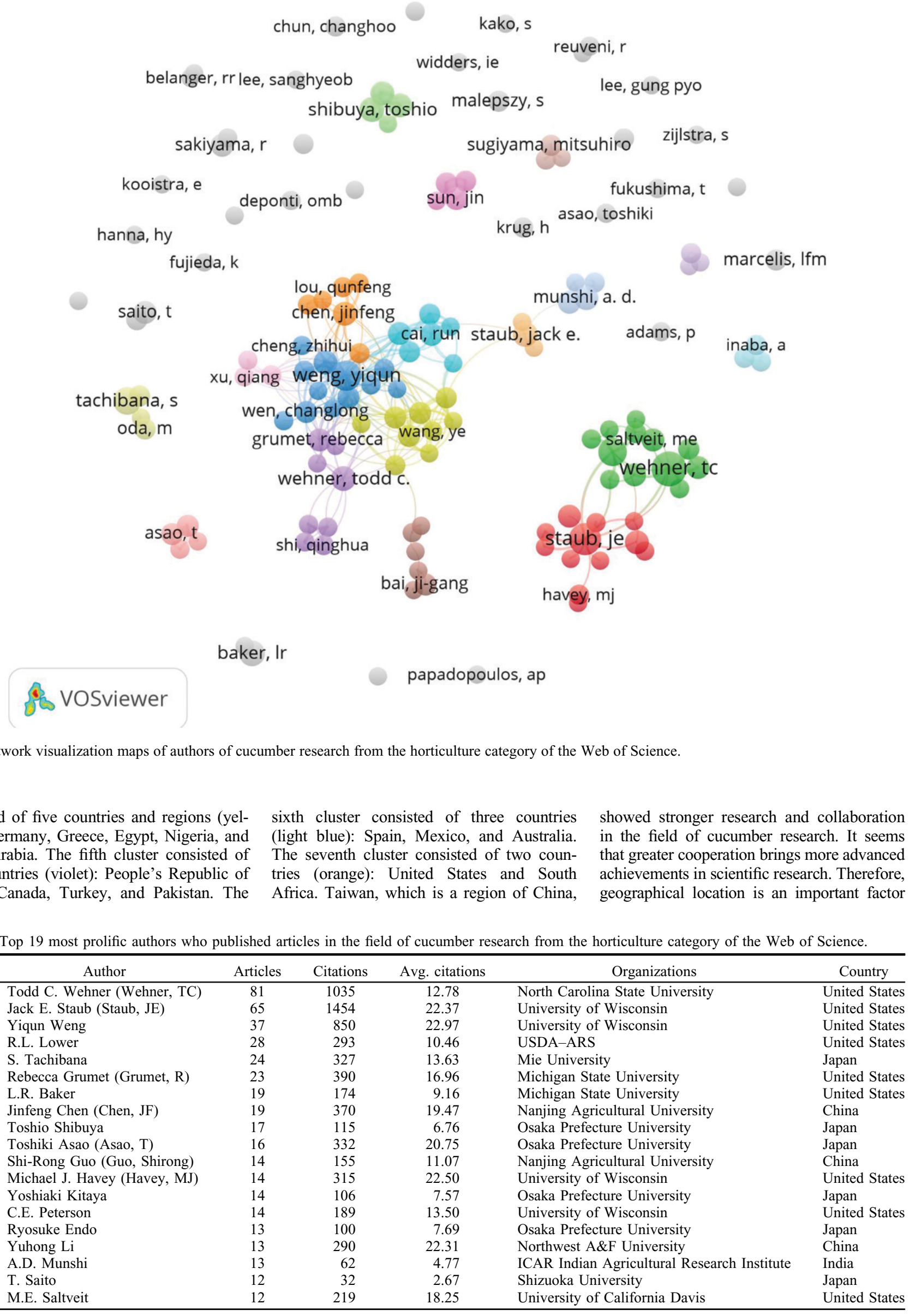


Table 5. Top 20 countries/regions publishing articles in the field of cucumber research from the horticulture category of the Web of Science.

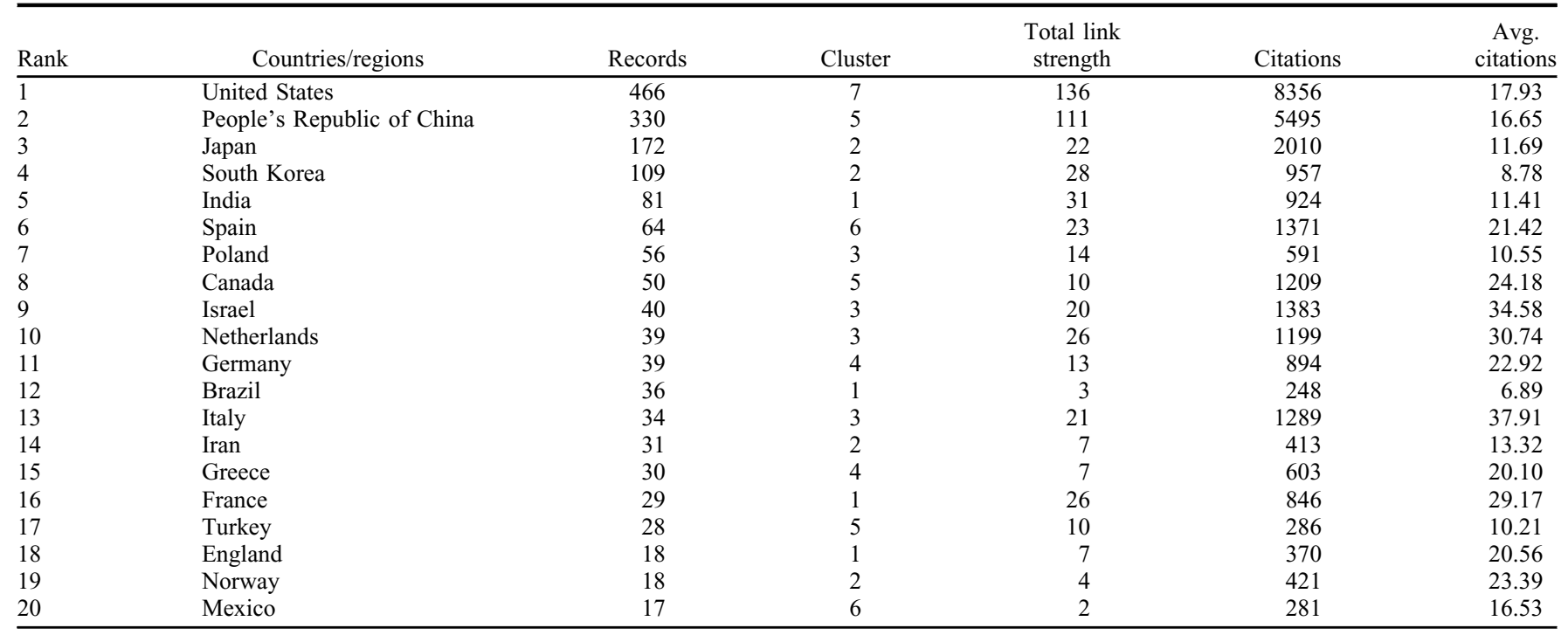

that determines international cooperation. The increasing international exchanges have promoted academic communications (Tang et al., 2018).

Organization coauthorship analysis. According to the publication data, a total of 1094 organizations published 2030 publications. The organization coauthorship analysis reflected the degree of communication between institutions as well as the influential institutions in this field (Reyes-Gonzalez et al., 2016). Table 6 lists the top 22 organizations and institutions that had more than 16 publications. These organizations are mainly focused in China (eight organizations), the United States (seven organizations), Japan (two organizations), Israel (one organization), Canada (one organization), India (one organization), South Korea (one organization), and Greece (one organization). The University of Wisconsin, North Carolina State University, U.S. Department of Agriculture-Agricultural Research Service (USDA-ARS), Michigan State University, and Nanjing Agricultural University are the top five organizations that have had articles published. The organizations of Agriculture Research Organization, Shandong Agricultural University, Agricultural University of Athens, University of Wisconsin, and Cornell University had the highest average number of citations per article.

Of the 1094 organizations, there were 119 organizations that met the minimum threshold of five; however, 88 organizations were connected to each other (Fig. 5). The VOSviewer software divided these 88 institutions into 11 clusters using different colors. Geographical localization is an important factor for partnership and joint ventures.

All keywords co-occurrence analysis. Of the 6672 keywords, there were only 621 keywords that met the threshold more than five times. These were separated into eight main cluster viewpoints of cucumber research from the horticulture category of the WoS (Fig. 6). The top 20 co-occurrence keywords (occurring more than 55 times) were cucumber, cucumis sativus, growth, plants, tomato,

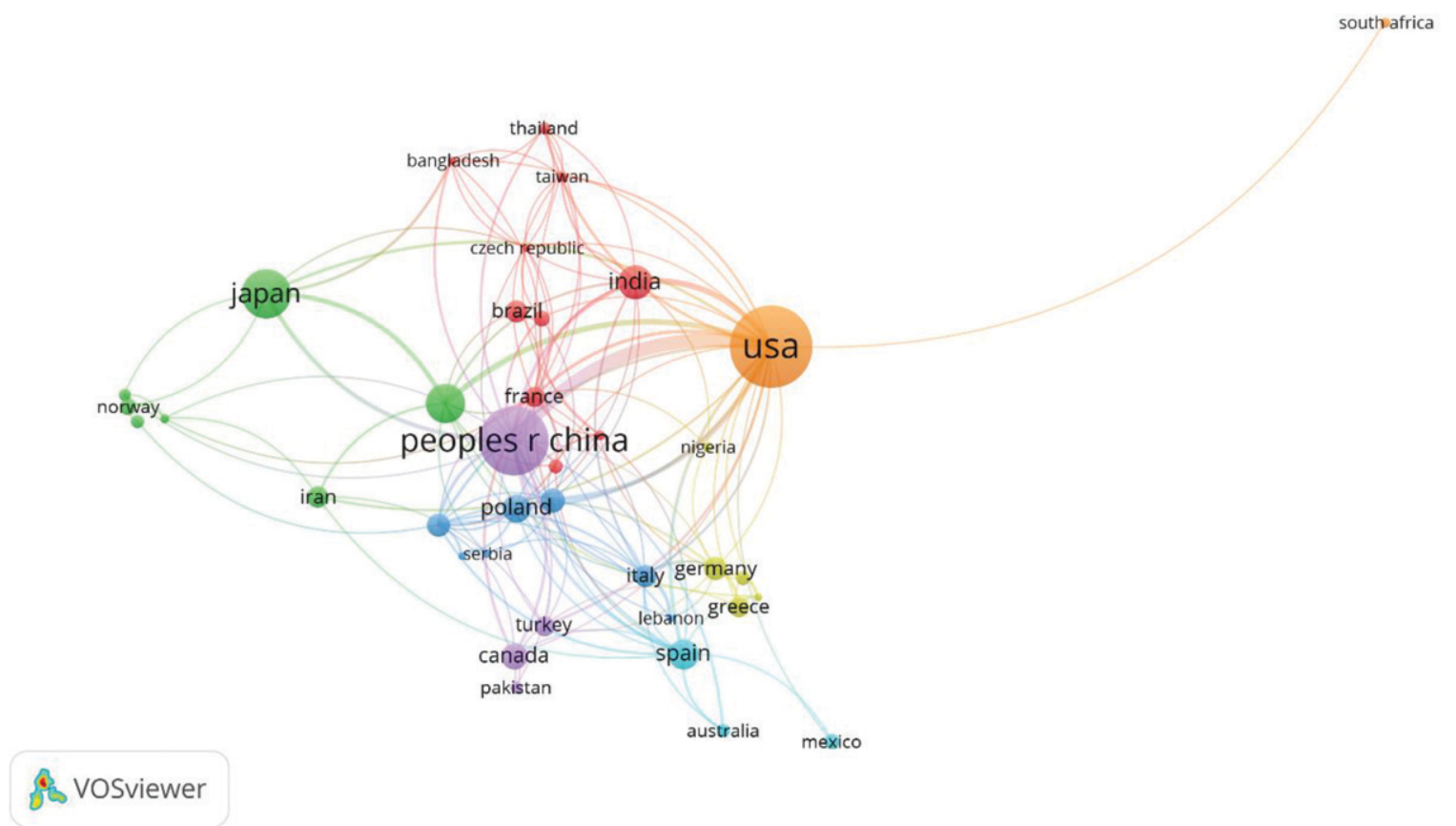

Fig. 4. The country coauthorship network of cucumber research from the horticulture category of the Web of Science with 38 nodes and seven clusters. 
Table 6. Top 22 organizations publishing articles in the field of cucumber research from the horticulture category of the Web of Science.

\begin{tabular}{|c|c|c|c|c|c|c|}
\hline Rank & Organizations & Records & TLS & Citations & Avg. C & Country \\
\hline$\overline{1}$ & University of Wisconsin & 103 & 128 & 2318 & 22.50 & $\overline{\text { United States }}$ \\
\hline 2 & North Carolina State University & 76 & 22 & 936 & 12.32 & United States \\
\hline 3 & USDA-ARS (ARS) & 64 & 108 & 1380 & 21.56 & United States \\
\hline 4 & Michigan State University & 53 & 24 & 1111 & 20.96 & United States \\
\hline 5 & Nanjing Agricultural University & 48 & 40 & 691 & 14.40 & China \\
\hline 6 & Shandong Agricultural University & 33 & 22 & 872 & 26.42 & China \\
\hline 7 & China Agricultural University & 31 & 32 & 629 & 20.29 & China \\
\hline 8 & Northwest Agriculture and Forest University & 31 & 61 & 463 & 14.94 & China \\
\hline 9 & Chinese Academy of Agricultural Sciences & 30 & 36 & 622 & 20.73 & China \\
\hline 10 & Cornell University & 25 & 17 & 557 & 22.28 & United States \\
\hline 11 & University of Florida & 25 & 12 & 385 & 15.40 & United States \\
\hline 12 & Shanghai Jiao Tong University & 24 & 30 & 352 & 14.67 & China \\
\hline 13 & Agricultural Research Organization & 22 & 11 & 1002 & 45.55 & Israel \\
\hline 14 & Osaka Prefecture University & 20 & 1 & 122 & 6.10 & Japan \\
\hline 15 & Agriculture and Agri-Food Canada & 19 & 5 & 327 & 17.21 & Canada \\
\hline 16 & Indian Agricultural Research Institute & 18 & 10 & 145 & 8.06 & India \\
\hline 17 & Shimane University & 18 & 6 & 357 & 19.83 & Japan \\
\hline 18 & Zhejiang University & 18 & 6 & 361 & 20.06 & China \\
\hline 19 & University of Georgia & 17 & 11 & 230 & 13.53 & United States \\
\hline 20 & Agricultural University of Athens & 16 & 5 & 396 & 24.75 & Greece \\
\hline 21 & Seoul National University & 16 & 15 & 216 & 13.50 & South Korea \\
\hline 22 & Yangzhou University & 16 & 14 & 112 & 7.00 & China \\
\hline
\end{tabular}

Avg. $\mathrm{C}=$ average citations; $\mathrm{TC}=$ total citations.

yield, resistance, quality, expression, identification, photosynthesis, temperature, tolerance, leaves, disease resistance, stress, inheritance, fruit, Arabidopsis, and genome.

The same data were arranged by the period of cucumber research from the horticulture category of the WoS (Fig. 7). According to the manual for VOSviewer version 1.6.16 (Van Eck and Waltman, 2020), blue colors indicate older research topics, and yellow and green colors indicate more recent topics of interest. When blue is used for topics, it does not mean that the topic is no longer researched; instead, blue usually indicates that, on average, the topic was intensely investigated previously, but now more attention has shifted toward other topics.

Visualizations of large datasets (big data) offer exploratory information regarding the current state of a scientific field or discipline as well as indicate possible developments in the future. The top 20 keywords are listed and ranked in each cluster in Fig. 6.

The first cluster (red) focused on inheritance analyses and gene expression. It included keywords such as expression, identification, inheritance, arabidopsis, genome, gene, cucurbitaceae, markers, genes, quantitative trait loci, sativus, sativus L., map, QTL analysis, loci, DNA, evolution, linkage, diversity, and genetic diversity.

The second cluster (green) focused on the metabolism and tolerance to stress of the plant. The keywords were ranked as tolerance, leaves, stress, fruit, cucumis sativus L., accumulation, light, seedlings, oxidative stress, storage, arabidopsis-thaliana, CI, geneexpression, injury, metabolism, acid, ethylene, hydrogen-peroxide, chlorophyll fluorescence, and abscisic-acid.

The third cluster (blue) focused on plant growth and fruit quality. It included keywords such as growth, tomato, yield, quality, photosynthesis, temperature, responses, salinity, soil, greenhouse, management, nitrogen, crops, grafting, lettuce, leaf, salt tolerance, soilless culture, fruit-quality, and efficiency.

The fourth cluster (yellow) focused on cucumber disease resistance and biocontrol management. The keywords included cucumber, disease resistance, induction, powdery mildew, biological-control, disease, salicylic-acid, vegetable breeding, plant growth, infection, biological control, biocontrol, damping-off, induced resistance, cucurbits, root, systemic acquired-resistance, systemic resistance, downy mildew, and induced systemic resistance.

The fifth cluster (violet) focused on cucumber grafting cultivars. It included keywords such as cucumis sativus, cucumis-sativus, watermelon, sativus L, cucumis-sativus L, cultivars, rootstock, water, vegetables, citrullus lanatus, maize, transformation, culture, pickling cucumber, plant-regeneration, fruits, toxicity, cytokinins, higher plants, pollination, and pumpkin.

The sixth cluster (light blue) focused on cucumber mosaic virus and disease resistance. It included keywords such as resistance, melon, protein, tobacco, cucumber mosaic virus, pepper, cucumis melo, plant, cmv, cucumber mosaic-virus, muskmelon, sequence, squash, field, lycopersicon-esculentum, potyvirus, virus resistance, coat protein, cucumber-mosaic-virus, capsicum annuum, and diseases.

The seventh cluster (orange) focused on cucumber nutrient solution and cucumber allelopathy. The keywords included hydroponics, rice, cucumber cucumis-sativus, nutrient solution, germination, vegetable crops, proteins, autotoxicity, systems, root exudates, allelopathy, cucumber (cucumis

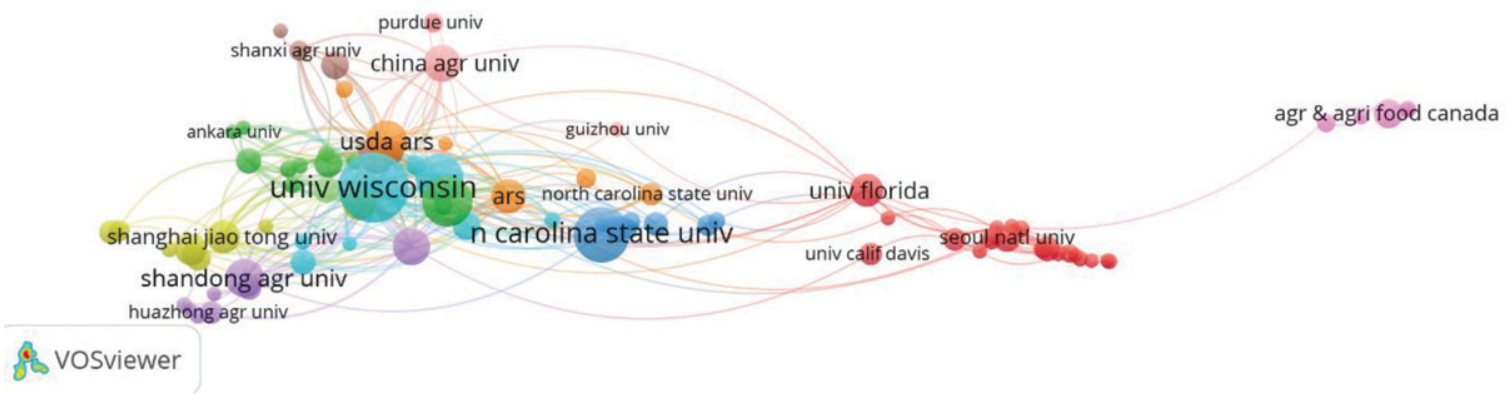

Fig. 5. The organization coauthorship network of cucumber research from the horticulture category of the Web of Science. 


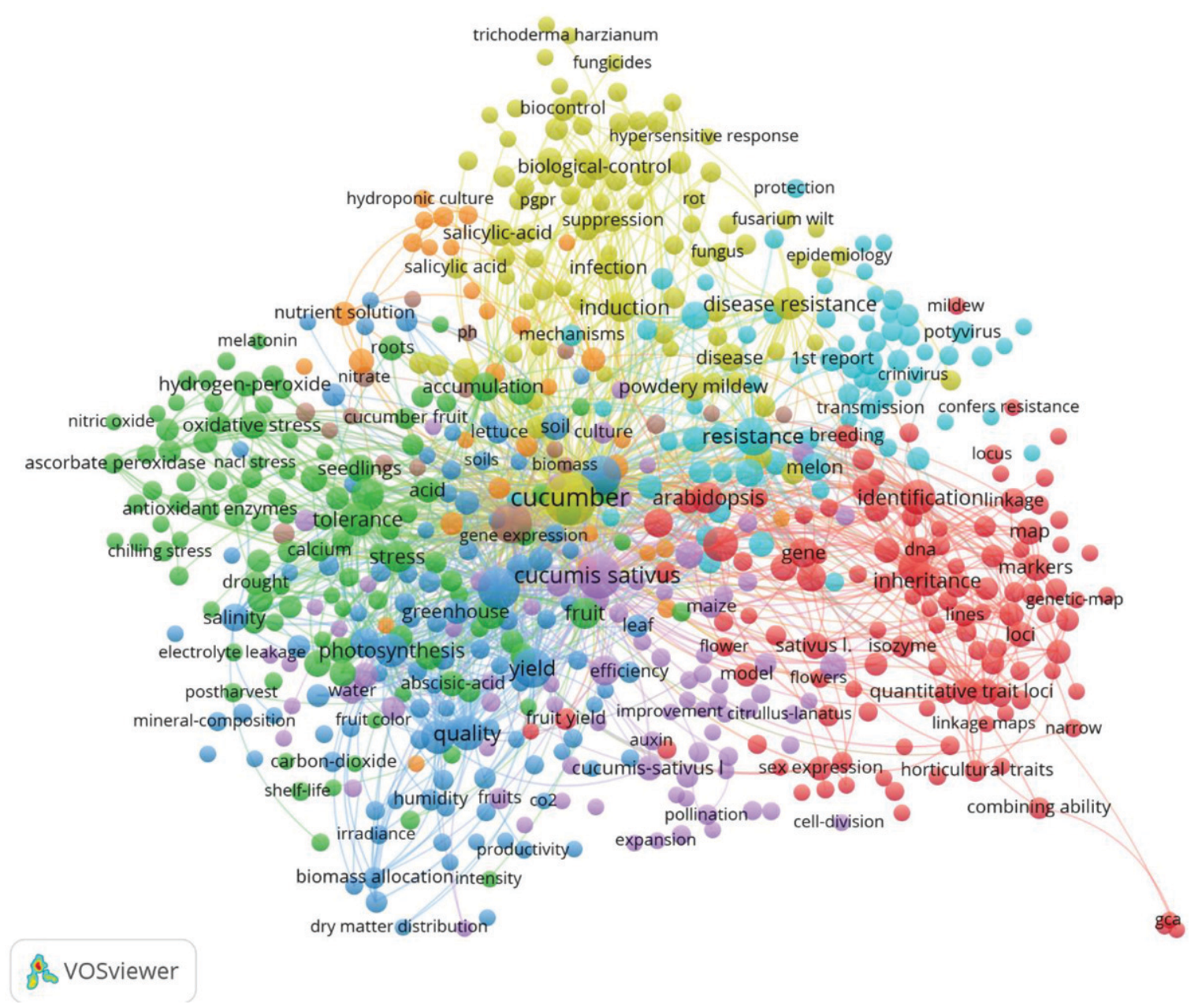

Fig. 6. VOSviewer co-occurrence network visualization mapping of the most frequent keywords (minimum of five occurrences) for cucumber research from the horticulture category of the Web of Science.

sativus L.), corn substances, activatedcharcoal, bell pepper, hydroponic culture, activated charcoal, allelochemicals, and bioassay.

The eighth cluster (brown) focused on plants nutrition. The keywords included plants, nutrition, nitrate, susceptibility, assimilation, nitrate reductase, amino-acids, ammonium, greenhouses, nutrient, podosphaera xanthii, zinc, availability, biomass, elevated $\mathrm{CO}_{2}, \mathrm{pH}$, and podosphaera-xanthii.

Top articles based on Essential Science Indicators. The top articles are the sum of hot articles and highly cited articles based on the Clarivate Analytics Essential Science Indicators (ESI). A highly cited article is an article that belongs to the top $1 \%$ of articles in a research field published during a specified year. A hot article is an article published within the past 2 years that was cited a number of times during the most recent 2-month period, thus placing it in the top $0.1 \%$ of articles in the same field. The Essential Science Indicators database includes a period of more than 11 years (1 Jan. 2010-31 Dec. 2020).

Based on the ESI database, these top articles are six highly cited articles (Table 7) that have been published in Scientia Horticulturae (Ahammed et al., 2020; Schwarz et al.,
2010; Z.W. Zhang et al., 2020; T.G. Zhang et al., 2020) and Theoretical and Applied Genetics (Lu et al., 2014; Pan et al., 2020) (Table 7).

The most frequently cited articles. A citation analysis has been performed to provide a supplementary index to determine the impact of scientific studies and identify studies, researchers, and the most renowned institutions focusing on the theme. Although several articles have been published, a relatively small number of individuals account for a large proportion of the citations within the period. The total number of citations of the eight most frequently cited articles is more than 150 (Fig. 8). These eight articles have been published in the following four journals: HortScience (Lee, 1994), Scientia Horticulturae (Carmen Martinez-Ballesta et al., 2010; Colla et al., 2010; Feng et al., 2010; Schwarz et al., 2010), Postharvest Biology and Technology (Qin and Lu, 2008), and European Journal of Plant Pathology (De Meyer et al., 1998; Zehnder et al., 2001). The citations of these articles increased every year until 2020, but their rates of increase are different (Fig. 8). The most cited article (blue line) was published in HortScience (Lee, 1994). An article published in Scientia Horticulturae (Schwarz et al., 2010) had highest number of citations per year (22.08; red line); it was also the most highly cited article based on ESI (Table 7). The number of times that an article is cited is considered a good quantitative measure of the impact of an article.

\section{Conclusions}

This study analyzed 2030 articles and review articles of cucumber research from the horticulture category of the WoS. These articles were mainly written in English $(92.81 \%)$ and were from 5630 authors, 80 countries/territories, and 1094 organizations, and they were published in 46 journals and book series. The top five core journals were ranked as Scientia Horticulturae, HortScience, Journal of the American Society for Horticultural Science, European Journal of Plant Pathology, and Horticulture Journal (Journal of the Japanese Society for Horticultural Science). The top five countries and regions were the United States, People's Republic of China, Japan, South Korea, and India. The top five 


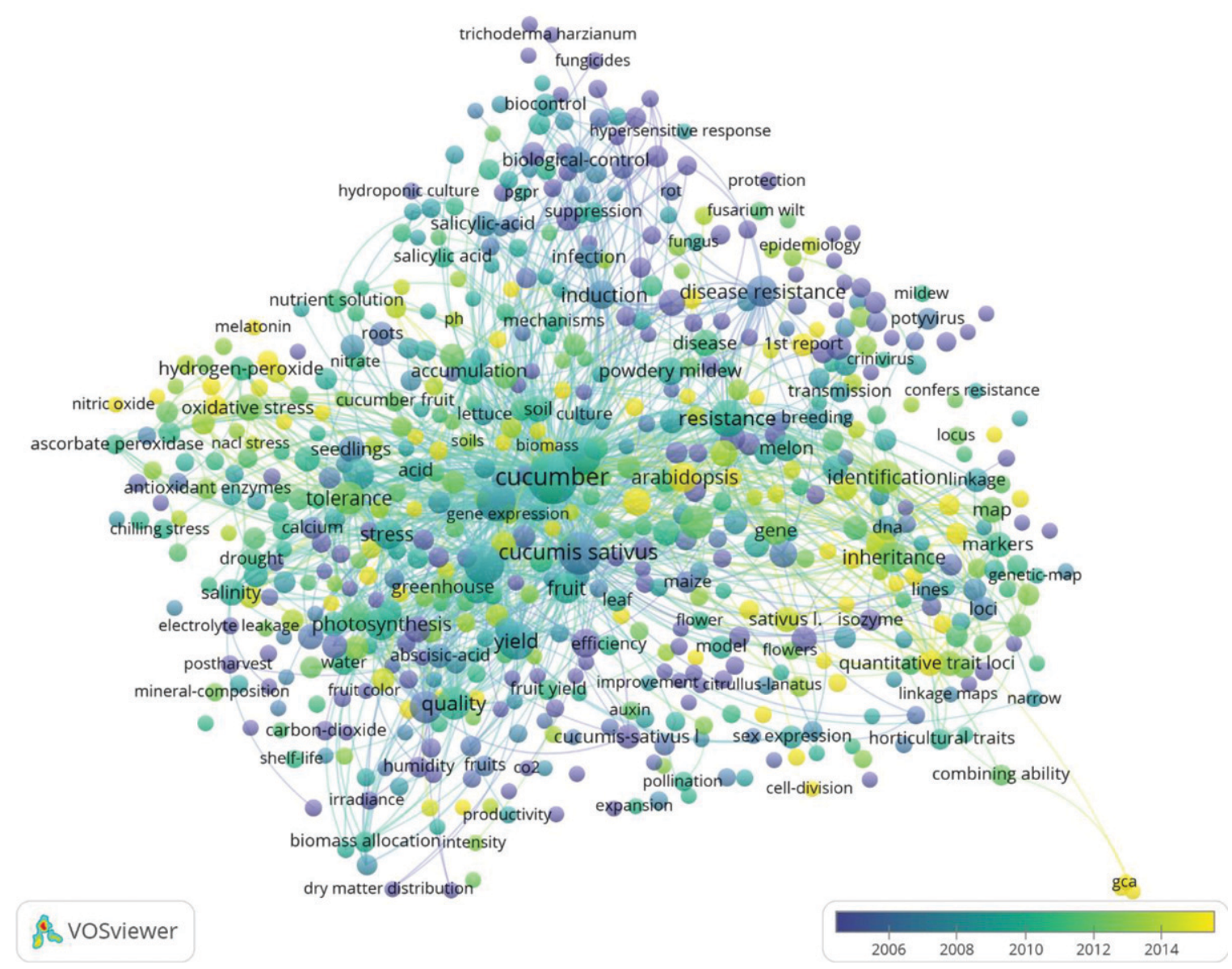

Fig. 7. VOSviewer co-occurrence overlay visualization mapping of most frequent keywords (minimum of five occurrences) for cucumber research from the horticulture category of the Web of Science.

organizations were the University of Wisconsin, North Carolina State University, USDA-ARS, Michigan State University, and Nanjing Agricultural University. The top five authors were Todd C. Wehner (Wehner, TC), Jack E. Staub (Staub, JE),
Yiqun Weng, R.L. Lower, and S. Tachibana. All keywords of the cucumber research from the horticulture category

Table 7. Top 6 highly cited articles according to the ESI.

\begin{tabular}{|c|c|c|c|}
\hline Rank & References & $\mathrm{TC}$ & ACPY \\
\hline 1 & $\begin{array}{l}\text { Schwarz, Dietmar; Rouphael, Youssef; Colla, Giuseppe; Venema, Jan Henk, } 2010 . \\
\text { Grafting as a tool to improve tolerance of vegetables to abiotic stresses: Thermal stress, } \\
\text { water stress and organic pollutants. Scientia Horticulturae } 127(2 \mathrm{SI}): 162-171 . \\
\text { https://doi.org/10.1016/j.scienta.2010.09.016. }\end{array}$ & 265 & 22.08 \\
\hline 2 & $\begin{array}{l}\text { Lu, Hongfeng; Lin, Tao; Klein, Joel; Wang, Shenhao; Qi, Jianjian; Zhou, Qian; Sun, } \\
\text { Jinjing; Zhang, Zhonghua; Weng, Yiqun; Huang, Sanwen, 2014. QTL-seq identifies an } \\
\text { early flowering QTL located near Flowering Locus T in cucumber. Theoretical and } \\
\text { Applied Genetics 127(7):1491-1499. https://doi.org/10.1007/s00122-014-2313-z. }\end{array}$ & 127 & 15.88 \\
\hline 3 & $\begin{array}{l}\text { Ahammed, Golam Jalal; Wu, Meijuan; Wang, Yaqi; Yan, Yaru; Mao, Qi; Ren, Jingjing; } \\
\text { Ma, Ronghui; Liu, Airong; Chen, Shuangchen, 2020. Melatonin alleviates iron stress by } \\
\text { improving iron homeostasis, antioxidant defense and secondary metabolism in cucumber. } \\
\text { Scientia Horticulturae 265:109205. https://doi.org/10.1016/j.scienta.2020.109205. }\end{array}$ & 33 & 16.5 \\
\hline 4 & $\begin{array}{l}\text { Zhang, Zhengwei; Wu, Pei; Zhang, Wenbo; Yang, Zhifeng; Liu, Huiying; Ahammed, Golam } \\
\text { Jalal; Cui, Jinxia, 2020. Calcium is involved in exogenous NO-induced enhancement of } \\
\text { photosynthesis in cucumber (Cucumis sativus L.) seedlings under low temperature. } \\
\text { Scientia Horticulturae 261:108953. https://doi.org/10.1016/j.scienta.2019.108953. }\end{array}$ & 18 & 9 \\
\hline 5 & $\begin{array}{l}\text { Pan, Yupeng; Wang, Yuhui; McGregor, Cecilia; Liu, Shi; Luan, Feishi; Gao, Meiling; } \\
\text { Weng, Yiqun, 2020. Genetic architecture of fruit size and shape variation in } \\
\text { cucurbits: a comparative perspective. Theoretical and Applied Genetics 133(1):1-21. } \\
\text { https://doi.org/10.1007/s00122-019-03481-3. }\end{array}$ & 15 & 7.5 \\
\hline 6 & $\begin{array}{l}\text { Zhang, Tengguo; Shi, Zhongfei; Zhang, Xiaohua; Zheng, Sheng; Wang, Juan; Mo, } \\
\text { Jiangnan, 2020. Alleviating effects of exogenous melatonin on salt stress in cucumber. } \\
\text { Scientia Horticulturae 262:109070. https://doi.org/10.1016/j.scienta.2019.109070. }\end{array}$ & 11 & 5.5 \\
\hline
\end{tabular}

$\mathrm{ACPY}=$ average citations per year; ESI $=$ Essential Science Indicators database; $\mathrm{TC}=$ total citations. 


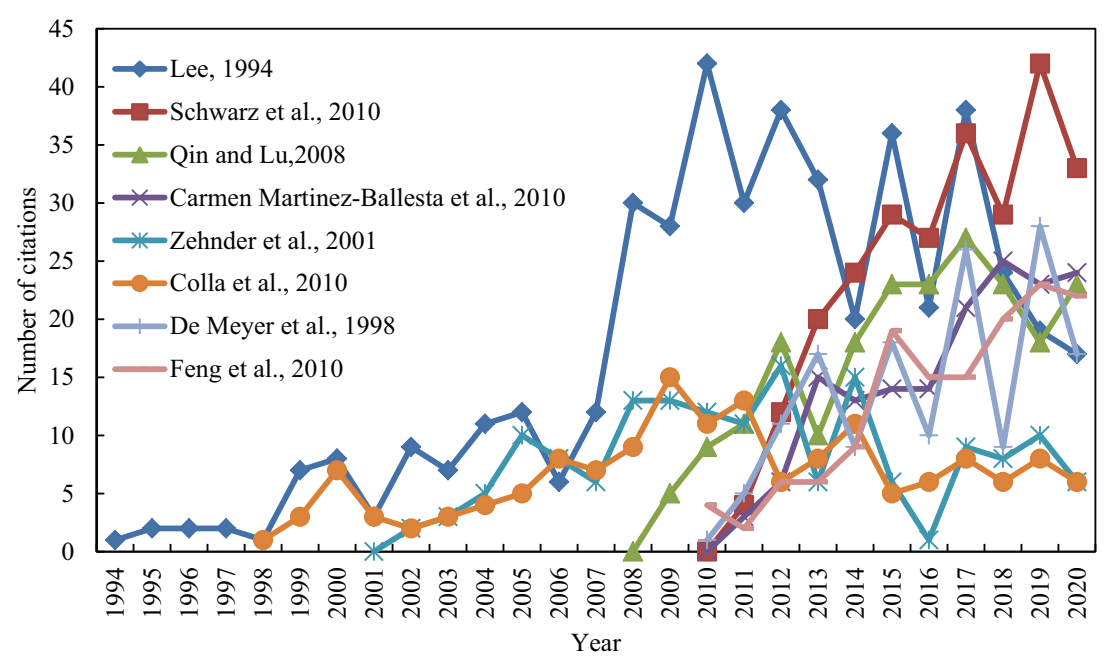

Fig. 8. Comparison of the citations per year of the eight most cited articles and their initial publications until 29 Mar. 2021.

were separated into eight clusters of different research topics. The analyses and visualizations reported herein offer exploratory information regarding the current status of a scientific field or discipline as well as indicate possible developments in the future.

\section{Literature Cited}

Ahammed, G.J., M.J. Wu, Y.Q. Wang, Y.R. Yan, Q. Mao, J.J. Ren, R.H. Ma, A.R. Liu, and S.C. Chen. 2020. Melatonin alleviates iron stress by improving iron homeostasis, antioxidant defense and secondary metabolism in cucumber. Scientia Hort. 265:109205, doi: 10.1016/ j.scienta.2020.109205.

Barnes, W.C., C.N. Clayton, and J.M. Jenkins. 1946. The development of downy mildewresistant cucumbers. Proc. Amer. Soc. Hort. Sci. 47:357-360.

Belmonte-Ureña, L.J., J.A. Garrido-Cardenas, and F. Camacho-Ferre. 2020. Analysis of world research on grafting in horticultural plants. HortScience 55(1):112-120, doi: 10.21273/ HORTSCI14533-19.

Carmen Martinez-Ballesta, M., C. Alcaraz-Lopez, B. Muries, C. Mota-Cadenas, and M. Carvajal. 2010. Physiological aspects of rootstock-scion interactions. Scientia Hort. 127(2 SI):112-118, doi: $10.1016 /$ j.scienta.2010.08.002.

Che, G. and X.L. Zhang. 2019. Molecular basis of cucumber fruit domestication. Curr. Opin. Plant Biol. 47:38-46, doi: 10.1016/j.pbi.2018.08.006.

Chen, Q.M., G.H. Yu, X.Y. Wang, X.N. Meng, and C.M. Lv. 2021. Genetics and resistance mechanism of the cucumber (Cucumis sativus L.) against powdery mildew. J. Plant Growth Regul. 40:147-153, doi: 10.1007/s00344-02010075-7.

Clarivate, 2021. Essential science indicators help: about essential science indicators, <http://esi. help.clarivate.com/Content/home.htm $>$.

Colla, G., Y. Rouphael, C. Leonardi, and Z.L. Bie. 2010. Role of grafting in vegetable crops grown under saline conditions. Scientia Hort. 127(2 SI):147-155, doi: 10.1016/j.scienta. 2010.08.004.

Dalla Via, J. and S. Baric. 2012. Tree fruit growing-research and production in Germany: A statistical and bibliometric analysis of the period 1950-2010. Erwerbs-Obstbau 54(1):

De Meyer, G., J. Bigirimana, Y. Elad, and M. Hofte 1998. Induced systemic resistance in Trichoderma harzianum T39 biocontrol of Botrytis cinerea. Eur. J. Plant Pathol. 104(3):279-286, doi: 10.1023/A:1008628806616.

Elango, B. and Y.S. Ho. 2017. A bibliometric analysis of highly cited papers from India in Science Citation Index Expanded. Curr. Sci. 112(8):1653-1658, doi: $10.18520 / \mathrm{cs} / \mathrm{v} 112 / 108 / 1653-1658$.

Elango, B. and Y.S. Ho. 2018. Top-cited articles in the field of tribology: A bibliometric analysis. COLLNET Journal of Scientometrics and Information Management 12(2):289-307, doi: 10.1080/09737766 . 2018.1529125 .

FAOSTAT. 2020. Food and Agriculture Data Food and Agriculture Organization of the United Nations, Rome, Italy. Yang, and H.N. Xu. 2010. Silicon supplementation ameliorated the inhibition of photosynthesis and nitrate metabolism by cadmium $(\mathrm{Cd})$ toxicity in Cucumis sativus L. Scientia Hort. 123(4):521-530, doi: 10.1016/j.scienta.2009. 10.013 .

Gusmini, G., and T.C. Wehner. 2008. Fifty-five years of yield improvement for cucumber, melon, and watermelon in the United States. HortTechnology 18(1):9-12, doi: 10.21273/

Hirsch, J.E. 2005. An index to quantify an individual's scientific research output. Proc. Natl. Acad. Sci. USA 102(46):16569-16572, doi: 10.1073/pnas.0507655102.

Jamali, H.R., C.C. Steel, and E. Mohammadi. 2020. Wine research and its relationship with wine production: A scientometric analysis of global trends. Austral. J. Grape Wine Res. 26(2):130-138, doi: 10.1111/ajgw.12422.

Khan, A., D. Khan, and F. Akbar. 2020. Bibliometric analysis of publications on research into cotton leaf curl disease. Discoveries (Craiova) 8(2):E109, doi: 10.15190/d.2020.6.

Kolle, S.R., T.H. Shankarappa, and T.B. Manjunatha Reddy. 2018. Trends in mango research as seen through Science Citation Expanded Index of Web of Science. Erwerbs-Obstbau 60(3): 261-270, doi: 10.1007/s10341-018-0367-9.

Kolle, S.R., T.H. Shankarappa, and Y.S. Ho. 2017. expanded - subject category of horticulture: A 11-30, doi: 10.1007/s10341-011-0155-2.

Feng, J.P., Q.H. Shi, X.F. Wang, M. Wei, F.J. HORTTECH.18.1.9. Highly cited articles in science citation index bibliometric analysis. Erwerbs-Obstbau 59(2): 133-145, doi: 10.1007/s10341-016-0308-4.

Kulak, M., A. Ozkan, and R. Bindak. 2019. A bibliometric analysis of the essential oil-bearing plants exposed to the water stress: How long way we have come and how much further? Scientia Hort. 246:418-436, doi: 10.1016/ j.scienta.2018.11.031.

Lee, J.M. 1994. Cultivation of grafted vegetables 1. current status, grafting methods, and benefits. HortScience 29(4):235-239, doi: 10.21273/ HORTSCI.29.4.235.

Liu, H.J., C.Y. Yin, Z.Z. Gao, and L.Z. Hou. 2021. Evaluation of cucumber yield, economic benefit and water productivity under different soil matric potentials in solar greenhouses in North China. Agr. Water Mgt. 243:106442, doi: 10.1016/j.agwat.2020.106442

Lu, H.F., T. Lin, J. Klein, S.H. Wang, J.J. Qi, Q. Zhou, J.J. Sun, Z.H. Zhang, Y.Q. Weng, and S.W. Huang. 2014. QTL-seq identifies an early flowering QTL located near Flowering Locus T in cucumber. Theor. Appl. Genet. 127(7):1491-1499, doi: 10.1007/s00122-014-2313-z.

Meira, D., L.G. Woyann, A.H. Bozi, A.S. Milioli, E. Beche, M.C. Panho, L.A. Madella, F. Barrionuevo, V.S. Marchioro, and G. Benin. 2020. Asian soybean rust: A scientometric approach of Phakopsora pachyrhizi studies. Euphytica 216(8):133, doi: 10.1007/s10681-020-02667-X.

Nanasato, Y. and Y. Tabei. 2020. A method of transformation and current progress in transgenic research on cucumbers and Cucurbita species. Plant Biotechnol. 37:141-146, doi: 10.5511/plantbiotechnology.20.0225a.

Pan, Y.P., Y.H. Wang, C. McGregor, S. Liu, F.S Luan, M.L. Gao, and Y.Q. Weng. 2020. Genetic architecture of fruit size and shape variation in cucurbits: A comparative perspective. Theor. Appl. Genet. 133(1):1-21, doi: 10.1007/ s00122-019-03481-3.

Qin, J.W. and R.F. Lu. 2008. Measurement of the optical properties of fruits and vegetables using spatially resolved hyperspectral diffuse reflectance imaging technique. Postharvest Biol Technol. 49(3):355-365, doi: 10.1016/ j.postharvbio.2008.03.010.

Raparelli, E., and D. Lolletti. 2020. Research, innovation and development on Corylus avellana through the bibliometric approach. Intl. J. Fruit Sci. 20(sup3):S1280-S1296, doi: 10.1080/15538 362.2020.1784076.

Reyes-Gonzalez, L., C.N. Gonzalez-Brambila, and F. Veloso. 2016. Using coauthorship and citation analysis to identify research groups: A new way to assess performance. Scientometrics 108(3):1171-1191, doi: 10.1007/s11192-0162029-8.

Schwarz, D., Y. Rouphael, G. Colla, and J.H. Venema. 2010. Grafting as a tool to improve tolerance of vegetables to abiotic stresses: Thermal stress, water stress and organic pollutants. Scientia Hort. 127(2 SI):162-171, doi: 10.1016/ j.scienta.2010.09.016.

Stopar, K., M. Mackiewicz-Talarczyk, and T. Bartol. 2021. Cotton fiber in web of science and scopus: Mapping and visualization of research topics and publishing patterns. J. Nat. Fibers 18(4):547-558, doi: 10.1080/15440478.2019.1636742.

Sun, J. and B.Z. Yuan. 2020a. Mapping of the world rice research: A bibliometric analysis of top papers during 2008-2018. Annals of Library and Information Studies 67(1):56-66.

Sun, J. and B.Z. Yuan. 2019. Visualization analysis of research on rice with fertilizer from the 'agronomy' category based on Citespace. Curr. Sci. 117(9):1449-1458, doi: 10.18520/cs/v117/ i9/1449-1458 
Sun, J. and B.Z. Yuan. 2020b. Bibliometric mapping of top papers in Library and Information Science based on the Essential Science Indicators Database. Malays. J. Libr. Inf. Sci. 25(2):61-76, doi: 10.22452/mjlis.vol25no2.4.

Sun, J. and B.Z. Yuan. 2020c. Mapping of top papers in the subject category of Water Resources based on the Essential Science Indicators. Annals of Library and Information Studies 67(2):90-102.

Sun, J. and B.Z. Yuan. 2021. Trend and research status of agronomy based on the Essential Science Indicators during 2009-2019. Agron. J. 113(2):2184-2194, doi: 10.1002/agj2.20628.

Tang, M., H.C. Liao, Z.J. Wan, E. HerreraViedma, and A. Rosen Marc. 2018. Ten years of sustainability (2009 to 2018): a bibliometric overview. Sustainability 10(5):1655, doi: $10.3390 /$ su10051655.

Tatry, M.V., D. Fournier, B. Jeannequin, and F. Dosba. 2011. Tools for analyzing and mapping scholarly publications not indexed by the Web of Science: The case of fruit and vegetable publications by the French National Institute for Agricultural Research (INRA). Fruits 66(2):131-140, doi: 10.1051/fruits/2011022.

Van Eck, N.J. and L. Waltman. 2010. Software survey: VOSviewer, a computer program for bibliometric mapping. Scientometrics 84(2): 523-538, doi: 10.1007/s11192-009-0146-3.

Van Eck, N.J. and L. Waltman. 2020. Manual for VOSviewer version 1.6.16. Univeristeit Leiden, Leiden.

Velasco-Muñoz, J.F., J.A. Aznar-Sánchez, L.J. Belmonte-Ureña, and M.J. López-Serrano. 2018a. Advances in water use efficiency in agriculture: A bibliometric analysis. Water 10(4):377, doi: 10.3390/w10040377.

Velasco-Muñoz, J.F., J.A. Aznar-Sánchez, L.J. Belmonte-Ureña, and I.M. Román-Sánchez. 2018b. Sustainable water use in agriculture: A review of worldwide research. Sustainability 10(4):1084, doi: 10.3390/su10041084.

Wambu, E.W. and Y.S. Ho. 2016. A bibliometric analysis of drinking water research in Africa. Water SA 42(4):612-620, doi: 10.4314/ wsa.v42i4.12.

Wang, S.L., S.K. Seong, X.G. Ye, C.F. He, S.Y. Kwon, and P.S. Choi. 2015. Current status of genetic transformation technology developed in cucumber (Cucumis sativus L.). J. Integr. Agr. 14(3):469-482, doi: 10.1016/S2095-3119(14) 60899-6.

Wang, Y.H., K.L. Bo, X.F. Gu, J.S. Pan, Y.H. Li, J.F. Chen, C.L. Wen, Z.H. Ren, H.Z. Ren, X.H. Chen, R. Grumet, and Y.Q. Weng. 2020. Molecularly tagged genes and quantitative trait loci in cucumber with recommendations for QTL nomenclature. Hort. Res. 7(1):3, doi: 10.1038/s41438-019-0226-3.

Wang, Y.P., W.Z. Liu, G. Li, W.M. Yan, and G.Y. Gao. 2019. A bibliometric analysis of soil and water conservation in the loess tablelandgully region of China. Water 11(1):20, doi: 10.3390/w11010020.

White-Gibson, A., B. O'Neill, D. Cooper, M. Leonard, and B. O'Daly. 2019. Levels of evidence in pelvic trauma: A bibliometric analysis of the top 50 cited papers. Ir. J. Med. Sci. 188(1):155-159, doi: 10.1007/s11845-0181818-x.

Yeung, A.W.K., N.T. Tzvetkov, G. Zengin, D.D. Wang, S.W. Xu, G. Mitrovic, M. Brncic, S. Dall'Acqua, V. Pirgozliev, A. Kijjoa, M.I. Georgiev, and A.G. Atanasov. 2019. The berries on the top. J. Berry Res. 9(1):125-139, doi: $10.3233 /$ JBR-180357.

Yuan, B.Z. and J. Sun. 2019. Bibliometric and mapping of top papers in the subject category of green and sustainable science and technology based on ESI. COLLNET Journal of Scientometrics and Information Management
13(2):269-289, doi: 10.1080/09737766.2020. 1716643.

Yuan, B.Z. and J. Sun. 2020a. Bibliometric analysis of research on the maize based on top papers during 2009-2019. COLLNET Journal of Scientometrics and Information Management 14(1):75-92, doi: 10.1080/09737766.2020. 1787110.

Yuan, B.Z. and J. Sun. 2020b. Mapping the scientific research on maize or corn: A bibliometric analysis of top papers during 2008-2018. Maydica 65(2):M7.

Yuan, B.-Z., Z.-L. Bie, and J. Sun. 2021. Bibliometric analysis of global research on muskmelon (Cucumis melo L.) based on Web of Science. HortScience 56(8):867-874, doi: 10.21273/ HORTSCI15827-21.

Zehnder, G.W., J.F. Murphy, E.J. Sikora, and J.W. Kloepper. 2001. Application of rhizobacteria for induced resistance. Eur. J. Plant Pathol. 107(1):39-50, doi: 10.1023/A:1008732400383.

Zhang, K.Y., J.S. Pan, Y. Chen, Y. Wei, H. Du, J.X. Sun, D. Lv, H.F. Wen, H.L. He, G. Wang, and R. Cai. 2021. Mapping and identification of CsSh5.1, a gene encoding a xyloglucan galactosyltransferase required for hypocotyl elongation in cucumber (Cucumis sativus L.). Theor. Appl. Genet. 134:979-991, doi: 10.1007/s00122-020-03754-2.

Zhang, T.G., Z.F. Shi, X.H. Zhang, S. Zheng, J. Wang, and J.N. Mo. 2020a. Alleviating effects of exogenous melatonin on salt stress in cucumber. Scientia Hort. 262:109070, doi: 10.1016/j.scienta.2019.109070.

Zhang, Z.W., P. Wu, W.B. Zhang, Z.F. Yang, H.Y. Liu, G.J. Ahammed, and J.X. Cui. 2020b. Calcium is involved in exogenous NO-induced enhancement of photosynthesis in cucumber (Cucumis sativus L.) seedlings under low temperature. Scientia Hort. 261:108953, doi: 10.1016/j.scienta.2019.108953. 